http://jmscr.igmpublication.org/home/ ISSN (e)-2347-176x ISSN (p) 2455-0450 crossref DOI: https://dx.doi.org/10.18535/jmscr/v8i4.76

Journal Of Medical Science And Clinical Research

\title{
A study on type2 diabetes mellitus patients in relation to lipid profile attending tertiary care hospital in Kanpur
}

\author{
Authors \\ Kushwaha J.S ${ }^{1}$, Giri Richa ${ }^{2}$, Mishra Dharmendra Kumar ${ }^{3 *}$, \\ Navin Mathiyalagan ${ }^{4}$, Sachan Mohit ${ }^{5}$ \\ ${ }^{1}$ Professor KPS PG Institute of Medicine GSVM Medical College Kanpur \\ ${ }^{2}$ Professor and Head, KPS PG Institute of Medicine GSVM Medical College Kanpur \\ ${ }^{3}$ Junior Resident, KPS PG Institute of Medicine GSVM Medical College Kanpur \\ ${ }^{4}$ Member of Royal College of Physicians, London and edinburg \\ ${ }^{5}$ Associate Professor KPS PG Institute of Medicine GSVM Medical College Kanpur \\ *Corresponding Author \\ Dr Dharmendra Kumar Mishra
}

Junior Resident, Department of Medicine (KPS Institute) GSVM Medical College Kanpur 208002, India

Abstract
Background: Diabetes Mellitus refers to a group of metabolic disorder, characterised by high blood sugar
and disturbance of carbohydrate, fat and protein metabolism due to absolute or relative deficiency of
insulin secretion or insulin action or together. Both lipid profile and diabetes is predictors for metabolic
disturbances including dyslipidaemia, hypertension, cardiovascular diseases. Lipids play a vital role in the
pathogenesis of diabetes mellitus and dyslipidemia as a metabolic abnormality is frequently associated with
it.
Methods: Study was conducted on 120 patients ( 62 males and 58 females) of age group 30 to 70 years of
diagnosed type 2 Diabetes Mellitus. Lipid abnormality and relationship between different parameters like
routine, blood sugar, HbAlC level and lipid profile in type 2 Diabetic Mellitus patients was done.
Study Period: January 2018 to October 2019.
Result: Study concluded that out of total study subject having t2dm about $80 \%)$ had abnormal lipid profile
and $20 \%$ patients had normal lipid profile.
Keywords: type 2, diabetes mellitus, triglycerides, low density lipoprotein, high density lipoprotein.

\section{Introduction}

Diabetes mellitus is a common metabolic disorder characterized by absolute or relative deficiencies in insulin secretion and/or insulin action associated with chronic hyperglycemia and disturbances of carbohydrate, lipid and protein metabolism associated with absolute or relative deficiency of insulin secretion or insulin action or together ${ }^{2}$. In diabetes patients, complications are mainly due to chronic hyperglycemia that exerts its injurious to health effects through several mechanisms: dyslipidemia, platelet activation, and altered endothelial metabolism. Both lipid profile and diabetes is predictors for metabolic disturbances including dyslipidaemia, hypertension, cardiovascular diseases. Lipids play a vital role in the pathogenesis of diabetes mellitus and dyslipidemia as a metabolic abnormality is 
frequently associated with diabetes mellitus. Diabetic dyslipidemia is more atherogenic than in dyslipidemia in general. Patients with HbA1c value $>7.0 \%$ had significantly higher value of Triglycerides cholesterol, Triacylglycerol, LDL-C, LDL-C/HDL-C ratio, non-HDL-C and TC/HDL-C ratio as compared to the patients with $\mathrm{HbA} 1 \mathrm{c} \leq$ $7.0 \% .^{6}$. Increased hepatic secretion of large triglyceride-rich VLDL and impaired clearance of VLDL appears to be of central importance in the pathophysiology of this dyslipidemia. Male are at higher risk group than females due to dyslipidemia $^{8}$. Triglycerides and TG/HDL-C were independent Diabetes Mellitus risk factors; and of the two, TG/HDL-C was a stronger risk factor. The Diabetes Mellitus discriminatory power of triglyceride and TG/HDL-C was poor; therefore, it is recommended that they be used in combination with other risk factors. Diabetes mellitus incidence increased with ascending risk score ${ }^{9}$.Subjects with an LDL-C $<100 \mathrm{mg} / \mathrm{dl}$, presence of metabolic dyslipidemia in adults with diabetes is associated with an increased risk of coronary heart disease ${ }^{11}$. Diabetic dyslipidemia is one of important complication of type 2 diabetes mellitus (T2DM). Blood lipid parameters (e.g., Triglyceride; total cholesterol; high-density lipoprotein cholesterol; low-density lipoprotein cholesterol) are atherogenic. Atherogenic Index of Plasma defined (AIP), are important indexes in predicting risk of obesity, lipid abnormality and T2DM 21.

\section{Aim}

To investigate the lipid profile in patients of Type 2 Diabetes Mellitus.

\section{Objectives}

1. To estimate the lipid profile (Serum cholesterol, Serum triglyceride and Serum ldl, serum vldl, serum hdl levels) in patients of Type 2 Diabetes Mellitus.

2. To study the relationship between Diabetes Mellitus and various lipid parameters in study subjects.

\section{Material and methods}

Study was conducted on 120 patients between 3070 years of age. The male patients were 80 and female were 40 . The patients were diagnosed of type 2 diabetes mellitus. Study subjects were taken from IPD and OPD of KPS institute of Medicine, LLR Hospital, GSVM Medical College Kanpur and consent was obtained before the start of study. The study Period was from January 2018 to October 2019.The study was observational, cross sectional, hospital based study and most suitable statistical tools were applied for data analysis.

\section{Inclusion Criteria}

- Subjects with previously diagnosed T2DM.

\section{Exclusion Criteria}

- Type 1 Diabetes Mellitus

- T2 DM patients with no history of DKA/Insulin therapy/OHA/ contraceptive (in female) therapy.

- Previous history of lipid diorders or Treatment with lipostatic drugs

- Pregnancy

- Acute or chronic infection

- Malignancy

- Kidney disease (GFR $<30 \mathrm{ml} / \mathrm{min} / 1.732$ $\mathrm{m}^{2}$ )

- Any other kidney pathology other than diabetic kidney disease.

\section{Investigations}

- Routine investigations

- Blood sugar

-Fasting

-Post Prandial

- HbA1c

- Lipid profile

-Serum Total Cholesterol

-Serum Triglycerides

-Serum LDL

-Serum HDL 


\section{Diagnosis of Diabetes (ADA 2011) \\ Pre Diabetes}

HbA1c value-5.7-6.4\%

Fasting blood sugar 100-125 mg/dl (5.6-6.9 mmmole/L)

\section{Diabetes-}

Fasting blood sugar more than $126 \mathrm{mg} / \mathrm{dl}$ (7.0mmol/L).

Fasting is defined as no calorie intake for at least 8 hours OR 2 -hrs Prandial Glucose more than 200 $\mathrm{mg} / \mathrm{dl}(11.1 \mathrm{mmol} / \mathrm{L})$ during OGTT or

$\mathrm{HbA} 1 \mathrm{C}>6.5 \%$.

Statistical Analysis- Data obtained from the study group was compiled and tabulated on MS Excel sheet and Master Table was made accordingly.

\section{Observations}

\section{General Profile of Study}

In present study most number of patients were comes under 35 to 60 years of age group. Out of which $66.66 \%$ were males (80) and $33.33 \%$ were females (40). $85.8 \%$ (103) were hindus and $14.2 \%$ (17) were muslims.

Table No 1 Mean Value and Standard Deviation of Various Parameters

\begin{tabular}{|l|c|c|}
\hline & MEAN & S.D. \\
\hline S.CHOL & 187.25 & 34.66 \\
\hline S.TRIG & 165.07 & 49.67 \\
\hline LDL & 101.1 & 40.73 \\
\hline HDL & 38.03 & 8.56 \\
\hline HB & 9.51 & 1.69 \\
\hline BSF & 196.26 & 60.92 \\
\hline BSPP & 263.88 & 73.52 \\
\hline
\end{tabular}

The mean value of Serum Cholesterol was 187.25 $\pm 34.66 \mathrm{mg} / \mathrm{dl}$., serum triglyceride mean value was $165.07 \pm 49.67 \mathrm{mg} / \mathrm{dl}$., Low density lipoprotein mean value was $101.1 \pm$ was $40.73 \mathrm{mg} / \mathrm{dl}$., high density lipoprotein mean value was $38.03 \pm$ was $8.56 \mathrm{mg} / \mathrm{dl}$ and haemoglobin mean value was
$9.51 \pm 1.69 \mathrm{~g} / \mathrm{dl}$. The Blood sugar fasting mean value was $196.26 \pm 60.92 \mathrm{mg} / \mathrm{dl}$. And blood sugar post prandial mean value was $263.88 \pm$ $73.52 \mathrm{mg} / \mathrm{dl}$

Table -2 Distribution of blood glucose and glycosylated haemoglobin values between the T2DM group $(\mathrm{n}=120)$

\begin{tabular}{|l|c|c|c|}
\hline & GROUP & MEAN & $\begin{array}{c}\text { STANDARD } \\
\text { DEVIATION }\end{array}$ \\
\hline $\begin{array}{l}\text { FASTING BLOOD } \\
\text { GLUCOSE(mg/dl) }\end{array}$ & T2DM & 196.28 & 60.92 \\
\hline $\begin{array}{l}\text { POST-PRANDIAL } \\
\text { BLOOD } \\
\text { GLUCOSE(mg/dl) }\end{array}$ & T2DM & 263.88 & 73.52 \\
\hline Hb1Ac(\%) & T2DM & 7.99 & 1.45 \\
\hline
\end{tabular}

The fasting blood glucose ( $\mathrm{mg} / \mathrm{dl})$ mean value was $196.28 \pm 60.92$ and post-prandial blood glucose $(\mathrm{mg} / \mathrm{dl})$ mean value was $263.88 \pm 73.52$. The Hb1Ac $(\%)$ mean value was $7.99 \pm 1.45$.

Chart No-1 Abnormal lipid profile chart in T2dl-

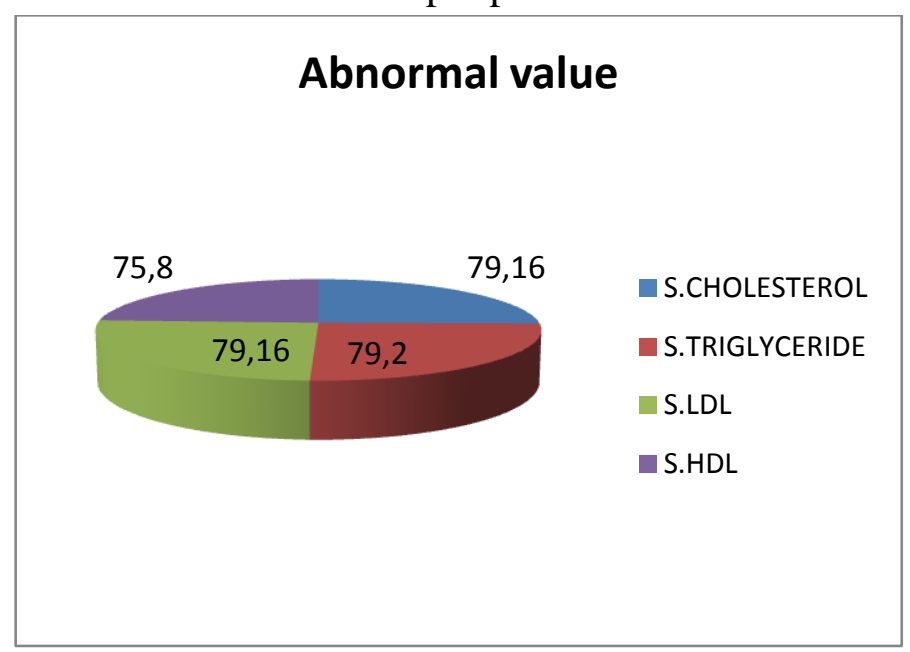

Different parameter mean value were as- the Total serum Cholesterol mean value was $166.7 \mathrm{mg} / \mathrm{dl}$, serum Triglyceride mean value was $179.15 \mathrm{mg} / \mathrm{dl}$, Serum high density Lipoprotein mean value was $52.7 \mathrm{mg} / \mathrm{dl}$, Serum Low density lipoprotein mean value was $79.6 \mathrm{mg} / \mathrm{dl}$.

Table-3 Distribution of total serum cholesterol in diabetic (T2DM) subjects $(n=120)$

\begin{tabular}{|l|c|c|c|c|c|c|}
\hline \multirow{3}{*}{ GENDER } & \multicolumn{6}{|c|}{ TOTAL SERUM CHOLESTEROL(mg/d) } \\
\cline { 2 - 7 } & \multicolumn{2}{|c|}{ ELEVATED(>200) } & \multicolumn{2}{c|}{ NORMAL(<200) } & \multicolumn{2}{c|}{ TOTAL } \\
\cline { 2 - 7 } & $\mathrm{N}$ & $\%$ & $\mathrm{~N}$ & $\%$ & $\mathrm{~N}$ & $\%$ \\
\hline MALE & 64 & $80.00 \%$ & 16 & $20.00 \%$ & 80 & $100 \%$ \\
\hline FEMALE & 31 & $77.50 \%$ & 9 & $22.50 \%$ & 40 & $100 \%$ \\
\hline TOTAL & 91 & $79.16 \%$ & 25 & $21.84 \%$ & 120 & $100 \%$ \\
\hline
\end{tabular}


Table no-4 Distribution of serum triglycerides in diabetic $(\mathrm{t} 2 \mathrm{dm})$ subjects $(\mathrm{n}=120)$

\begin{tabular}{|l|l|l|l|l|l|l|}
\hline \multirow{3}{*}{ GENDER } & \multicolumn{5}{l}{ Serum TRIGLYCERIDE(mg/dl) } \\
\cline { 2 - 7 } & ELEVATED(>200) & \multicolumn{2}{l|}{ NORMAL(<200) } & \multicolumn{2}{l|}{ TOTAL } \\
\cline { 2 - 7 } & $\mathrm{N}$ & $\%$ & $\mathrm{~N}$ & $\%$ & $\mathrm{~N}$ & $\%$ \\
\hline MALE & 65 & $81.25 \%$ & 15 & $18.75 \%$ & 80 & $100 \%$ \\
\hline FEMALE & 30 & $75.00 \%$ & 10 & $25.00 \%$ & 40 & $100 \%$ \\
\hline TOTAL & 73 & $79.20 \%$ & 25 & $20.80 \%$ & 120 & $100 \%$ \\
\hline
\end{tabular}

In total 120 subjects $73(79.20 \%)$ patients having abnormal and 25(20.80\%) patients having normal serum triglycerides level

Table no.-5 Distribution of Serum Ldl Cholesterol in diabetic (T2DM) subjects in the study group $(\mathrm{n}=120)$

\begin{tabular}{|l|c|c|c|c|c|c|}
\hline \multirow{3}{*}{ GENDER } & \multicolumn{6}{|c|}{ LDL $(\mathrm{mg} / \mathrm{dl})$} \\
\cline { 2 - 7 } & \multicolumn{2}{|c|}{ ELEVATED(>150) } & \multicolumn{2}{|c|}{ NORMAL(<150) } & \multicolumn{2}{c|}{ TOTAL } \\
\cline { 2 - 7 } & $\mathrm{N}$ & $\%$ & $\mathrm{~N}$ & $\%$ & $\mathrm{~N}$ & $\%$ \\
\hline MALE & 69 & $86.2 \%$ & 11 & $13.75 \%$ & 80 & $100 \%$ \\
\hline FEMALE & 26 & $65.00 \%$ & 14 & $35.00 \%$ & 40 & $100 \%$ \\
\hline TOTAL & 95 & $79.16 \%$ & 25 & $20.84 \%$ & 120 & $100 \%$ \\
\hline
\end{tabular}

In total 120 subjects 95(79.16\%) patients having high and 25(20.84\%) patients having normal serum LDL level

Table no-6 Distribution of Serum HDL cholesterol in diabetic(T2DM) subjects in the study group ( $\mathrm{n}=120)$

\begin{tabular}{|l|c|c|c|c|c|c|}
\hline \multirow{2}{*}{ GENDER } & \multicolumn{4}{|c|}{ HDL $(\mathrm{mg} / \mathrm{dl})$} \\
\cline { 2 - 7 } & \multicolumn{2}{|c|}{ Unfavorable(<40) } & \multicolumn{2}{|c|}{ NORMAL $(>40)$} & \multicolumn{2}{|c|}{ TOTAL } \\
\cline { 2 - 7 } & $\mathrm{N}$ & $\%$ & $\mathrm{~N}$ & $\%$ & $\mathrm{~N}$ & $\%$ \\
\hline MALE & 62 & $77.50 \%$ & 18 & $22.50 \%$ & 80 & $100 \%$ \\
\hline FEMALE & 29 & $72.50 \%$ & 11 & $27.50 \%$ & 40 & $100 \%$ \\
\hline TOTAL & 91 & $75.80 \%$ & 29 & $24.20 \%$ & 120 & $100 \%$ \\
\hline
\end{tabular}

In total 120 subjects $91(75.80 \%)$ patients having abnormal and 29(24.20\%) patients having favrorable serum HDL level

\section{Results}

Total 120 Type 2 Diabetic Mellitus patients were selected for study, majority of subjects belong to 35 to 60 years age group and $66.66 \%$ (80) of study subjects were males and $33.33 \%$ (40) were females. Majority of patients by religion were Hindus $(85.8 \%)$ and $14.2 \%$ were Muslims. The mean value of glycosylated $\mathrm{Hb}$ was $7.99 \% \pm 1.45$, mean value of fasting blood glucose was 196.28 $(\mathrm{mg} / \mathrm{dl}) \pm 60.92$ and post-prandial blood glucose $(\mathrm{mg} / \mathrm{dl})$ mean value was $263.88 \pm 73.52$. In lipid profile the total serum cholesterol mean value was $2.02 \pm 0.85$, total serum triglyceride mean value was179.15, total serum ldl mean value was 79.6, total serum hdl mean value was 52.7. In our study group $20.84 \%$ (25) of the study subjects have normal Serum cholesterol and 79.16\% (95) have high Serum cholesterol level. In our study group $20.80 \%$ (25) of the study subjects have normal Serum triglicerides and $79.20 \%$ (95) have high Serum triglicerides level. In our study group $79.16 \%$ (95) of the study subjects have high Serum ldl and 20.84\% (25) have normal Serum ldl level. In our study group $24.20 \%$ (29) of the study subjects have high Serum hdl and $75.80 \%$ (91) have low Serum hdl level

\section{Discussion}

Diabetes mellitus is the most important health problem in population worldwide and inspite of advances in treatment. A huge number of patients present with complications owing to poor glycaemic control. According to our results, about more than $70.0 \%$ of diabetic $(\mathrm{t} 2 \mathrm{dm})$ patients presented at least one lipid abnormality. The combination of elevated triglycerde and reduced 
HDL-cholesterol was the most prevalent of the combined lipid abnormalities, result similar to Stamouli M, Pouliakis A, Mourtzikou A et al. As diabetes mellitus, a multifactorial metabolic abnormality consisting of insulin resistance with compensatory hyperinsulinaemia,. Several studies showed that insulin affects the liver apolipoprotein production and regulates the enzymatic activity of lipoprotein lipase and cholesterol ester transport protein, which causes dyslipidemia in diabetes mellitus. The term diabetic dyslipidemia comprises a triad of raised triglycerides, reduced high density lipoprotein (HDL) and excess of small, dense low density lipoprotein (LDL) particles. In fact, the "low HDL cholesterol" or "hypoalpha" syndrome is the most frequent lipoprotein abnormality in coronary patients Rafael Bitzur, MD, Hofit Cohen et al. High triglyceride levels were seen in $26 \%$ to $64 \%$ of the participants, depending on glucose tolerance status. Low HDL-cholesterol levels were seen in all groups (>90\%). Significant linear trends were observed for high triglyceride-Cholesterol, high triglyceride and low HDL-cholesterol with increasing glucose intolerance. The relation of various lipid parameters like serum cholesterol, serum triglycerides, serum ldl and serum hdl in t2 diabetes mellitus support the findings of D. S. Kalsi, Jyoti Chopra, and AnchalSood and Aclan Ozder. The lipid abnormalities are prevalent in diabetes mellitus because insulin resistance or deficiency affects key enzymes and pathways in lipid metabolism. It has been proposed that the composition of lipid particles in diabetic dyslipidemia is more atherogenic than other types of dyslipidemia by Aclan Ozder The association between reduced HDL cholesterol levels and increased risk of heart disease is, on the other hand, well established, independently of triglyceride levels and other risk factors $\mathrm{He}$ $\mathrm{S}$, Wang $\mathrm{S}$, Chen $\mathrm{X}$ et al. Hypertension and dyslipidemia are major risk factors for cardiovascular disease, accounting for the highest morbidity and mortality. In the present study, we aimed to research association between serum lipid profile and blood glucose, hypothesizing that early detection and treatment of lipid abnormalities can minimize the risk for atherogenic cardiovascular disorder and cerebrovascular accident in patients with type 2 diabetes mellitus.

\section{Conclusion}

The present study suggested that common lipid abnormalities in diabetic dyslipidemia are hypercholesterolemia, hypertriglyceridemia and elevated LDL cholesterol. Present study included 120 subjects of Type 2 Diabetic Mellitus of age group 30 to 70 years. Majority of study subjects belong to 35 to 60 years age group both in case of males and females. Study concluded that out of total study subject having $\mathrm{t} 2 \mathrm{dm}$ about more than $70 \%$ were abnormal lipid profile. In our study subjects $79.16 \%(95)$ have high Serum cholesterol level, $79.20 \%(95)$ have high Serum triglicerides level, 79.16\%(95) have high Serum ldl and 75.80\%(91) have low Serum hdl level. Results suggest a high prevalence of dyslipidemia, which might be playing a major role in the development of cardiovascular diseases and cerebrovascular accidents among diabetic patients. The optimal care for diabetic patients should include routine monitoring of blood glucose and serum lipid profile. Efforts to achieve lifestyle changes, such as weight reduction, physical exercise and smoking cessation should be encouraged and initiated first and then followed by medication with lipid lowering drugs prescribed in evidencebased necessary conditions.

\section{Bibliography}

1. Stamouli M, Pouliakis A, Mourtzikou A, Skliris A, Panagiotou I, Mournianakis E, Totos G. Evaluation of the lipid profile in type 2 diabetes mellitus patients in Greece.Clin Lab. 2014;60(10):1593-600. .

2. AclanOzderLipid profile abnormalities seen in T2DM patients in primary healthcare in Turkey: a cross-sectional studyLipids Health Dis. 2014; 13: 183. 
3. Mooradian AD. Dyslipidemia in type 2 diabetes mellitus.Nat Clin Pract Endocrinol Metab. 2009 Mar;5(3):150-9.

4. He S, Wang S, Chen X, Jiang L, Peng Y, $\mathrm{Li}$ L, Wan L, Cui K.Higher ratio of triglyceride to high-density lipoprotein cholesterol may predispose to diabetes mellitus: 15-year prospective study in a general population. Metabolism. 2012 Jan;61(1):30-6.

5. Rafael Bitzur, MD, Hofit Cohen, MD, Yehuda Kamari, MD, Aviv Shaish, PHD, and DrorHarats, MDTriglycerides and HDL CholesterolDiabetes Care. 2009 Nov; 32(Suppl 2):S373-S377.

6. Bishwajit Bhowmik, Tasnima Siddiquee, Anindita Mujumder, Faria Afsana, Tareen Ahmed, Ibrahimu A. Mdala, Nayla Cristina do V. Moreira, AbulKalam Azad Khan, AkhtarHussain, Gerd HolmboeOttesen, and Tone Kristin Omsland Serum Lipid Profile and Its Association with Diabetes and Prediabetes in a Rural Bangladeshi PopulationInt J Environ Res Public Health. 2018 Sep; 15(9): 1944.

7. Choudhury KN, Mainuddin AK, Wahiduzzaman M, Islam SM. Serum lipid profile and its association with hypertension in Bangladesh.Vasc Health Risk Manag. 2014 Jun 30;10:327-32. doi: 10.2147/VHRM.S61019. eCollection 2014.

8. Krauss RM Lipids and lipoproteins in patients with type 2 diabetes.Diabetes Care. 2004 Jun;27(6):1496-504.

9. Rana JS, Liu JY, Moffet HH, Solomon MD, Go AS, Jaffe MG, Karter AJAm J Metabolic Dyslipidemia and Risk of Coronary Heart Disease in 28,318 Adults With Diabetes Mellitus and Low-Density Lipoprotein Cholesterol $<100 \quad \mathrm{mg} / \mathrm{dl}$. Cardiol. 2015 Dec 1;116(11):1700-4

10. Siraj ES, Seyoum B, Saenz C, Abdulkadir J. Lipid and lipoprotein profiles in
Ethiopian patients with diabetes mellitus. Metabolism. 2006 Jun;55(6):706-10.

11. Gadi R, Samaha FF. Dyslipidemia in type 2 diabetes mellitus.CurrDiab Rep. 2007 Jun;7(3):228-34

12. Santos-Gallego CG, Rosenson RS.Role of HDL in those with diabetes.CurrCardiol Rep. 2014 Aug;16(8):512.

13. He S, Wang S, Chen X, Jiang L, Peng Y, Li L, Wan L, Cui K. Higher ratio of triglyceride to high-density lipoprotein cholesterol may predispose to diabetes mellitus: 15-year prospective study in a general population. Metabolism. 2012 Jan; 61(1):30-6.

14. Giannini C, Santoro N, Caprio S, Kim G, Lartaud D, Shaw M, Pierpont B, Weiss R. The triglyceride-to-HDL cholesterol ratio: association with insulin resistance in obese youths of different ethnic backgrounds. Diabetes Care. 2011 Aug;34(8):1869-74.

15. Prashant Regmi, Prajwal Gyawali, Rojeet Shrestha, Manoj Sigdel, Kisun D Mehta, Shankar Majhi Pattern of Dyslipidemia in Type $\square$ Diabetic Subjects in Eastern Nepal .Journal of Nepal Association for Medical Laboratory Sciences P. 11-13

16. Lewis GF, Uffelman KD, Szeto LW, Weller B, Steiner G.Interaction between free fatty acids and insulin in the acute control of very low density lipoprotein production in humans.JClin Invest. 1995 Jan; 95(1):158-66.

17. Ram VinodMahato, Prajwal Gyawali, Pramod Psd. Raut, Prashant Regmi, Khelanand Psd. Singh, Dipendra Raj Pandeya and Prabin Gyawali Association between glycaemic control and serum lipid profile in type 2 diabetic patients: Glycated haemoglobin as a dual biomarker Biomedical Research (2011) Volume 22, Issue 3

18. TaskinenMR.Diabetic dyslipidaemia: from basic research to clinical practice. 
Diabetologia. 2003 Jun;46(6):733-49.

Epub 2003 May 28

19. Taskinen MR Diabetic dyslipidemia. Atheroscler Suppl. 2002 May;3(1):47-51.

20. Zhu XW, Deng FY, Lei SF Meta-analysis of Atherogenic Index of Plasma and other lipid parameters in relation to risk of type 2 diabetes mellitus.Prim Care Diabetes. 2015 Feb;9(1):60-7.

21. Zhu XW, Deng FY, Lei SF.Meta-analysis of Atherogenic Index of Plasma and other lipid parameters in relation to risk of type 2 diabetes mellitus.Prim Care Diabetes. 2015 Feb;9(1):60-7.

22. Elnasri HA, Ahmed AM. Patterns of lipid changes among type 2 diabetes patients in Sudan. East Mediterr Health J. 2008 MarApr;14(2):314-24.

23. D. S. Kalsi, Jyoti Chopra, and Anchal Sood Association of lipid profile test values, type-2 diabetes mellitus, and periodontitis Indian J Dent. 2015 Apr-Jun; 6(2): 81-84. 